\title{
Foreword of guest editor
}

\author{
Wei $\mathbf{W u}^{1}$
}

Published online: 29 September 2015

(c) Springer-Verlag Berlin Heidelberg 2015

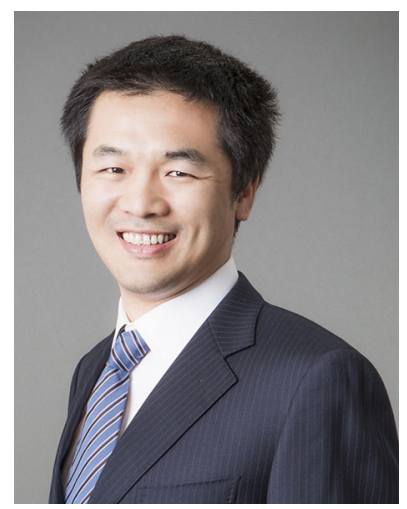

Wei Wu, USC Los Angeles

In this exciting special issue on "nanoimprint lithography," we got great supports from the nanoimprint community. We received invited and contribution papers from both academia and industry from three continents. On behave of the board of editors of Applied Physics A and guest editors

of this special issue, we would like to thank their supports and great scientific achievements. This issue covers a broad range of topics, from nanoimprint process to applications of nanoimprint, from theoretical investigation to experimental demonstrations, from mold manufacturing process to new nanoimprint resist, and from patterning on flexible substrates to patterning of 3D structures. After 20 years of fast growth, great progress has been made. Nanoimprint lithography has grown from a "smart invention" to a technology on the ITRS roadmap and with applications much beyond semiconductors. Twenty years is a milestone. We wish this special issue can, at least partially, take a snapshot of this vibrant technology at this moment. This snapshot not only celebrates the achievements over the last 20 years, but also gives the community an opportunity to contemplate on how to move the technology forward for the better years ahead.

Enjoy your special issue on nanoimprint lithography from Applied Physics A. Let's push hard and the next special issue will be even better!

Wei Wu

wu.w@usc.edu

1 University of Southern California, Los Angeles, CA, USA 